\title{
Compressive and Shear Buckling Analysis of Metal Matrix Composite Sandwich Panels Under Different Thermal Environments
}

William L. Ko and Raymond H. Jackson

JUNE 1993

(NASA-TM-4492) COMPRESSIVE AND

SHEAR BUCKLING ANALYSIS OF METAL MATRIX COMPOSITE SANDWICH PANELS UNOER OIFFERENT THERMAL ENVIRONMENTS (NASA) $23 \mathrm{P}$

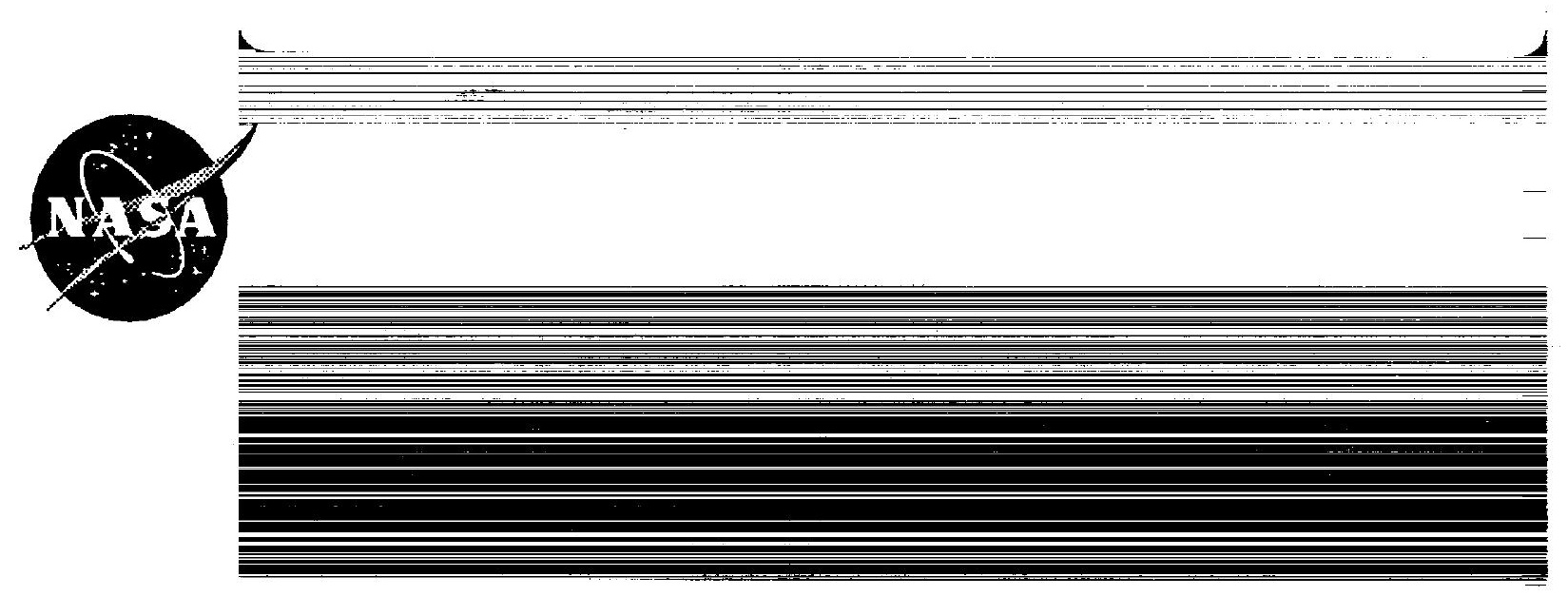


11 
NASA Technical Memorandum 4492

\section{Compressive and Shear \\ Buckling Analysis of \\ Metal Matrix Composite Sandwich Panels Under Different Thermal Environments}

William L. Ko and Raymond H. Jackson Dryden Flight Research Facility

Edwards, California

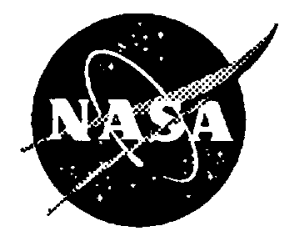

National Aeronautics and Space Administration

Office of Management

Scientific and Technical Information Program 
71 


\section{CONTENTS}

NOMENCLATURE

INTRODUCTION

METAL MATRIX COMPOSITE SANDWICH PANEL

COMBINED-LOAD BUCKLING EQUATION

EIGENVALUE SOLUTIONS

$\begin{array}{lr}\text { NUMERICAL RESULTS } & 7\end{array}$

Physical Properties of Panels $\ldots \ldots \ldots \ldots \ldots \ldots \ldots \ldots \ldots \ldots \ldots$

Buckling Curves $\ldots \ldots \ldots \ldots \ldots \ldots \ldots \ldots \ldots \ldots \ldots \ldots \ldots \ldots \ldots$

Conventional Plots $\ldots \ldots \ldots \ldots \ldots \ldots \ldots \ldots \ldots \ldots$



Buckling Interaction Surfaces $\ldots \ldots \ldots \ldots \ldots \ldots \ldots \ldots \ldots \ldots$

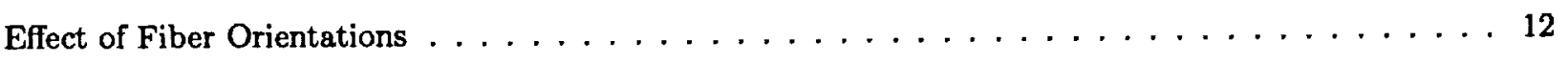

$\begin{array}{lr}\text { CONCLUSIONS } & 12\end{array}$

$\begin{array}{lr}\text { REFERENCES } & 13\end{array}$ 
11 


\title{
ABSTRACT
}

Combined inplane compressive and shear buckling analysis was conducted on fat rectangular sandwich panels using the Raleigh-Ritz minimum energy method with a consideration of transverse shear effect of the sandwich core. The sandwich panels were fabricated with titanium honeycomb core and laminated metal matrix composite face sheets. The results show that slightly slender (along unidirectional compressive loading axis) rectangular sandwich panels have the most desirable stiffness-to-weight ratios for aerospace structural applications; the degradation of buckling strength of sandwich panels with rising temperature is faster in shear than in compression; and the fiber orientation of the face sheets for optimum combined-load buckling strength of sandwich panels is a strong function of both loading condition and panel aspect ratio. Under the same specific weight and panel aspect ratio, a sandwich panel with metal matrix composite face sheets has much higher buckling strength than one having monolithic face sheets.

\section{NOMENCLATURE}

\author{
$A_{m n} \quad$ Fourier coefficient of trial function for $w, \mathrm{~m}$ (in.) \\ a \\ length of sandwich panel, $m$ (in.) \\ $a_{0} \quad$ edge length of square sandwich panel, $m$ (in.) \\ $a_{m n}^{i j} \quad$ coefficients of characteristic equations, no dimension \\ $b \quad$ width of sandwich panel, $m$ (in.) \\ $D^{*} \quad$ flexural stiffness parameter, $D=\frac{E_{\mathrm{Ti}} I_{s}}{1-\nu_{\mathrm{Ti}}^{2}}, \mathrm{~m}-\mathrm{N}$ (in-lb) \\ $D_{Q x}, D_{Q y} \quad$ transverse shear stiffnesses of sandwich core in the $x z$ and $y z$ planes, $D_{Q x}=G_{c x z} h_{c}$,

$$
D_{Q y}=G_{c y x} h_{c}, \mathrm{~N} /(\mathrm{m}-\mathrm{rad})[\mathrm{b} /(\mathrm{in}-\mathrm{rad})]
$$ \\ $D_{x}, D_{y} \quad$ longitudinal and transverse panel flexural stiffnesses, $D_{x}=E_{x} I_{s}, D_{y}=E_{y} I_{s}, \mathrm{~m}: \mathrm{N}$ (in-lb) \\ $\bar{D}_{x}, \bar{D}_{y} \quad$ panel flexural stiffnesses, $\bar{D}_{x}=D_{x} /\left(1-\nu_{x y} \nu_{y x}\right), \bar{D}_{y}=D_{y} /\left(1-\nu_{x y} \nu_{y x}\right), \mathrm{m}-\mathrm{N}$ (in-lb) \\ $D_{x y} \quad$ panel twisting stiffness, $D_{x y}=2 G_{x y} I_{s}, \mathrm{~m}-\mathrm{N}$ (in-lb) \\ $E_{\mathrm{Ti}} \quad$ Young's modulus of titanium material, $\mathrm{N} / \mathrm{m}^{2}\left(\mathrm{lb} / \mathrm{in}^{2}\right)$ \\ $E_{x}, E_{y} \quad$ Young's moduli of face sheets, $\mathrm{N} / \mathrm{m}^{2}\left(\mathrm{lb} / \mathrm{in}^{2}\right)$
}


$G_{c x z}, G_{c y z}$ shear moduli of sandwich core, $\mathrm{N} / \mathrm{m}^{2}\left(\mathrm{lb} / \mathrm{in}^{2}\right)$

$G_{x y} \quad$ shear modulus of face sheets, $\mathrm{N} / \mathrm{m}^{2}\left(\mathrm{lb} / \mathrm{in}^{2}\right)$

depth of sandwich panel = distance between middle planes of two face sheets, $\mathrm{cm}$ (in.)

$h_{c} \quad$ sandwich core depth, cm (in.)

$I_{s} \quad$ moment of inertia, per unit width, of two face sheets taken with respect to horizontal

centroidal axis (neutral axis) of the sandwich panel, $I_{s}=\frac{1}{2} t_{s} h^{2}+\frac{1}{6} t_{s}^{3}, \mathrm{~m}^{4} / \mathrm{m}\left(\mathrm{in}^{4} / \mathrm{in}\right.$.)

$i, j \quad$ indices, $1,2,3, \ldots$

$k_{x}, k_{y} \quad$ compressive buckling load factors in $x$ - and $y$-directions, $k_{x}=\frac{N_{x} a^{2}}{\pi^{2} D^{*}}, k_{y}=\frac{N_{y} a^{2}}{\pi D^{*}}$ (for $a=$ constant), no dimension

$k_{x y} \quad$ shear buckling load factor, $k_{x y}=\frac{N_{x y} a^{2}}{\pi^{2} D^{*}}$ (for $a=$ constant), no dimension

$\bar{k}_{x}, \bar{k}_{y} \quad$ modified compressive buckling load factors in $x$ - and $y$-directions, $\bar{k}_{x}=\frac{N_{x} a_{0}^{2}}{\pi^{2} D^{*}}=k_{x} \frac{b}{a}$,

$k_{y}=\frac{N_{y} a_{o}^{2}}{\pi^{2} D^{*}}=k_{y} \frac{b}{a}$ (for $a b=a_{o}^{2}=$ constant), no dimension

$\bar{k}_{x y}$

modified shear buckling load factor, $\bar{k}_{x y}=\frac{N_{x y} a_{o}^{2}}{\pi^{2} D^{*}}=k_{x y} \frac{b}{a}$ (for $a b=a_{o}^{2}=$ constant), no dimension

$m$

number of buckle half waves in $x$-direction

MMC metal matrix composite

$N_{x} \quad$ normal stress resultants in $x$-direction, $\mathrm{N} / \mathrm{m}(\mathrm{lb} / \mathrm{in}$.)

$N_{y} \quad$ normal stress resultants in $y$-direction, $\mathrm{N} / \mathrm{m}$ (lb/in.)

$N_{x y} \quad$ shear stress resultant, $\mathrm{N} / \mathrm{m}$ (lb/in.)

$n$

number of buckle half waves in $y$-direction

$P_{x} \quad$ compressive load in $x$-direction, N (lb)

$P_{y} \quad$ compressive load in $y$-direction, N (lb)

$Q \quad$ shear load, N (lb)

T temperature, ${ }^{\circ} \mathrm{C}\left({ }^{\circ} \mathrm{F}\right)$

$\mathrm{Ti} \quad$ titanium

$t_{s} \quad$ thickness of sandwich face sheets, $\mathrm{cm}$ (in.)

$w \quad$ panel deflection, $\mathrm{m}$ (in.)

$x, y, z \quad$ rectangular Cartesian coordinates

$\delta_{m n i j}$

special delta function obeying $m \neq i, n \neq j,(m \pm i)=$ odd, $(n \pm j)=$ odd, $\delta_{m n i j}=\frac{m n i j}{\left(m^{2}-i^{2}\right)\left(n^{2}-j^{2}\right)}$ 
fiber angle, deg

$\nu_{\mathrm{Ti}} \quad$ Poisson ratio of titanium material

$\nu_{x y}, \nu_{y x} \quad$ Poisson ratios of face sheets, also for sandwich panel

\section{INTRODUCTION}

Metal matrix composites (MMCs) have gained considerable popularity as one of the strongest candidates for hot structural applications. Typical hot structures are the airframes of hypersonic flight vehicles, gas turbine engine components, etc. The MMC system is attractive to the hot structures because it can meet the structures' service requirements. Namely, MMCs can operate at elevated temperatures and provide specific mechanical properties (i.e., high strength and stiffness). Taya and Arsenault have discussed all aspects of the thermomechanical behavior of the MMC system in great detail. ${ }^{1}$

The principal application of MMCs in hypersonic flight vehicles is in the form of sandwich constructions with the laminated MMCs used as face sheets. ${ }^{2}$ The sandwich structure offers low thermal conductivity in the sandwich thickness direction, a high stiffness-to-weight ratio, and the capability to reduce thermal stresses.

During service, the sandwich panel is under combined thermal and mechanical loading that could induce a critical situation of combined compressive and shear loading, the driving force of panel buckling. Before actual application of MMC sandwich panels as hot structural components, the buckling characteristics of the structural panels under different thermal environments must be fully understood. This paper analyzes the combined inplane-compressive and shear buckling behavior of MMC sandwich panels using the Raleigh-Ritz minimum energy method and shows how the combined load buckling strength varies with temperature levels, fiber orientation, and panel geometry.

\section{METAL MATRIX COMPOSITE SANDWICH PANEL}

Figure 1 shows a rectangular sandwich panel of length $a$ and width $b$, fabricated with titanium (Ti) honeycomb core of depth $h_{c}$ and laminated MMC face sheets of same thickness $t_{s}$. The sandwich panel is simply supported at 
its four edges, and is subjected to combined inplane compressive and shear loadings. The problem is to calculate buckling interaction curves for the panel and to examine how the combined load buckling strength of the panel changes with (1) thermal environment, (2) fiber orientation, and (3) panel aspect ratio.

\section{COMBINED-LOAD BUCKLING EQUATION}

The combined-load (inplane compression and shear) buckling characteristic equation developed by Ko and Jackson $^{3}$ for a four-edge simply supported anisotropic rectangular sandwich panel may be written as

$$
\frac{M_{m n}}{k_{x y}} A_{m n}+\sum_{i=1}^{\infty} \sum_{j=1}^{\infty} \delta_{m n i j} A_{i j}=0
$$

This equation was derived through the use of the Raleigh-Ritz method of minimization of the total potential energy of the sandwich panel with the effect of transverse shear taken into consideration.

In equation (1), $A_{m n}$ is the undetermined Fourier coefficient of the assumed function for panel deflection $w$ in the form

$$
w(x, y)=\sum_{m=1}^{\infty} \sum_{n=1}^{\infty} A_{m n} \sin \frac{m \pi x}{a} \sin \frac{n \pi y}{b}
$$

where $a$ and $b$, respectively, are the length and the width of the panel and $m$ and $n$, respectively, are the number of buckle half waves in the $x$ - and the $y$-directions. The $\delta_{m n i j}$ in equation (1) is a special delta function defined as

$$
\delta_{m n i j}=\frac{m n i j}{\left(m^{2}-i^{2}\right)\left(n^{2}-j^{2}\right)}
$$

that obeys the conditions $m \neq i, n \neq j,(m \pm i)=$ odd, and $(n \pm j)=$ odd. The stiffness factor $M_{m n}$ in equation (1) is defined as

$$
M_{m n}=\frac{a b}{32}\left\{k_{x}\left(\frac{m \pi}{a}\right)^{2}+k_{y}\left(\frac{n \pi}{b}\right)^{2}-\frac{a^{2}}{\pi^{2} D^{*}}[\underbrace{a_{m n}^{11}}_{\begin{array}{c}
\text { classical thin } \\
\text { plate theory term }
\end{array}}+\underbrace{\frac{a_{m n}^{12}\left(a_{m n}^{23} a_{m n}^{31}-a_{m n}^{21} a_{m n}^{33}\right)+a_{m n}^{13}\left(a_{m n}^{21} a_{m n}^{32}-a_{m n}^{22} a_{m n}^{31}\right)}{a_{m n}^{22} a_{m n}^{33}-a_{m n}^{23} a_{m n}^{32}}}_{\text {transverse shear effect terms }}]\right\}
$$

where the characteristic coefficients $a_{m n}^{i j}(i, j=1,2,3)$ appearing in equation (4) are defined as ${ }^{3}$

$$
a_{m n}^{11}=\bar{D}_{x}\left(\frac{m \pi}{a}\right)^{4}+\left(\bar{D}_{x} \nu_{y x}+\bar{D}_{y} \nu_{x y}+2 D_{x y}\right)\left(\frac{m \pi}{a}\right)^{2}\left(\frac{n \pi}{b}\right)^{2}+\bar{D}_{y}\left(\frac{n \pi}{b}\right)^{4}
$$




$$
\begin{aligned}
& a_{m n}^{12}=a_{m n}^{21}=-\left[\bar{D}_{x}\left(\frac{m \pi}{a}\right)^{3}+\frac{1}{2}\left(\bar{D}_{x} \nu_{y x}+\bar{D}_{y} \nu_{x y}+2 D_{x y}\right)\left(\frac{m \pi}{a}\right)\left(\frac{n \pi}{b}\right)^{2}\right] \\
& a_{m n}^{13}=a_{m n}^{31}=-\left[\bar{D}_{y}\left(\frac{n \pi}{b}\right)^{3}+\frac{1}{2}\left(\bar{D}_{x} \nu_{y x}+\bar{D}_{y} \nu_{x y}+2 D_{x y}\right)\left(\frac{m \pi}{a}\right)^{2}\left(\frac{n \pi}{b}\right)\right] \\
& a_{m n}^{22}=\bar{D}_{x}\left(\frac{m \pi}{a}\right)^{2}+\frac{D_{x y}}{2}\left(\frac{n \pi}{b}\right)^{2}+D_{Q x} \\
& a_{m n}^{23}=a_{m n}^{32}=\frac{1}{2}\left(\bar{D}_{x} \nu_{y x}+\bar{D}_{y} \nu_{x y}+D_{x y}\right)\left(\frac{m \pi}{a}\right)\left(\frac{n \pi}{b}\right) \\
& a_{m n}^{33}=\bar{D}_{y}\left(\frac{n \pi}{b}\right)^{2}+\frac{D_{x y}}{2}\left(\frac{m \pi}{a}\right)^{2}+D_{Q y}
\end{aligned}
$$

\section{EIGENVALUE SOLUTIONS}

Equation (1) forms a system of an infinite number of simultaneous equations associated with different values of $m$ and $n$. However, the number of equations written from equation (1) may be truncated up to a certain finite number as required for convergency of eigenvalue solutions.

Because $(m \pm i)=$ odd and $(n \pm j)=$ odd (eq. (3)), then $(m \pm i) \pm(n \pm j)=(m \pm n) \pm(i \pm j)=$ even. Thus, if $(m \pm n)=$ even, then $(i \pm j)$ must be even also. Likewise, if $(m \pm n)=$ odd, then $(i \pm j)$ must be odd. Therefore, there is no coupling between the even and odd cases in each equation written out from equation (1) for a particular set of $\{m, n\}$. If the $A_{m n}$ term in equation (1) is for $(m \pm n)=$ even, then the $A_{i j}$ terms in the same equation must be for $(i \pm j)=$ even also. If the $A_{m n}$ term is for $(m \pm n)=$ odd, then the $A_{i j}$ term must be for $(i \pm j)=$ odd also.

Thus, the set of simultaneous equations written out from equation (1) may be divided into two groups that are independent of each other: one group in which $(m \pm n)$ is even (symmetrical buckling), and the other group in which ( $m \pm n$ ) is odd (antisymmetrical buckling) ${ }^{3-7}$ For the deflection coefficients $A_{m n}$ to have nontrivial solutions for given values of $k_{x}, k_{y}$, and $\frac{b}{a}$, the determinant of the coefficients of the unknown $A_{m n}$ must vanish. The largest eigenvalue $\frac{1}{k_{x y}}$ thus found will give the lowest buckling load factor $k_{x y}$ as a function of $k_{x}, k_{y}$, and $\frac{b}{a}$. Thus, a family of buckling interaction curves in the $k_{x}-k_{x y}$ or in the $k_{y}-k_{x y}$ space may be generated with $\frac{b}{a}$ as a parameter. 
Representative characteristic equations (buckling equations) for $12 \times 12$ matrices written out from equation (1) are shown in equations (11) and (12) for the cases $(m \pm n)=$ even and $(m \pm n)=$ odd. $^{3}$

For $(m \pm n)=$ even (symmetric buckling):

\begin{tabular}{|c|c|c|c|c|c|c|c|c|c|c|c|c|}
\hline$m, n \backslash^{i, j}$ & $A_{11}$ & $A_{13}$ & $A_{22}$ & $A_{31}$ & $A_{15}$ & $A_{24}$ & $A_{33}$ & $A_{42}$ & $A_{51}$ & $A_{35}$ & $A_{44}$ & $A_{53}$ \\
\hline$m=1, n=1$ & $\frac{M_{u l}}{k_{x y}}$ & 0 & $\frac{4}{9}$ & 0 & 0 & $\frac{8}{45}$ & 0 & $\frac{8}{45}$ & 0 & 0 & $\frac{16}{225}$ & 0 \\
\hline$m=1, n=3$ & & $\frac{M_{13}}{k_{x y}}$ & $-\frac{4}{5}$ & 0 & 0 & $\frac{8}{7}$ & 0 & $-\frac{8}{25}$ & 0 & 0 & $\frac{16}{35}$ & 0 \\
\hline$m=2, n=2$ & & & $\frac{M_{22}}{k_{z y}}$ & $-\frac{4}{5}$ & $-\frac{20}{63}$ & 0 & $\frac{36}{25}$ & 0 & $-\frac{20}{63}$ & $\frac{4}{7}$ & 0 & $\frac{4}{7}$ \\
\hline$m=3, n=1$ & & & & $\frac{M_{31}}{k_{z y}}$ & 0 & $-\frac{8}{25}$ & 0 & $\frac{8}{7}$ & 0 & 0 & $\frac{16}{35}$ & 0 \\
\hline$m=1, n=5$ & & & & & $\frac{M_{1 s}}{k_{z y}}$ & $-\frac{40}{27}$ & 0 & $-\frac{8}{63}$ & 0 & 0 & $-\frac{16}{27}$ & 0 \\
\hline$m=2, n=4$ & & & & & & $\frac{M_{24}}{k_{z y}}$ & $-\frac{72}{35}$ & 0 & $-\frac{8}{63}$ & $\frac{8}{3}$ & 0 & $-\frac{120}{147}$ \\
\hline$m=3, n=3$ & & & & netry & & & $\frac{M_{3 z}}{k_{x y}}$ & $-\frac{72}{35}$ & 0 & 0 & $\frac{144}{49}$ & 0 \\
\hline$m=4, n=2$ & & & & & & & & $\frac{M_{v 2}}{k_{z y}}$ & $-\frac{40}{27}$ & $-\frac{120}{147}$ & 0 & $\frac{8}{3}$ \\
\hline$m=8, n=1$ & & & & & & & & & $\frac{M_{31}}{k_{x y}}$ & 0 & $-\frac{16}{27}$ & 0 \\
\hline$m=s, n=5$ & & & & & & & & & & $\frac{M_{35}}{k_{z y}}$ & $-\frac{80}{21}$ & 0 \\
\hline$m=4, n=4$ & & & & & & & & & & & $\frac{M_{x_{1}}}{k_{z_{y}}}$ & $-\frac{80}{21}$ \\
\hline$m=5, n=3$ & & & & & & & & & & & & $\frac{M_{53}}{k_{x y}}$ \\
\hline
\end{tabular}

where the nonzero off-diagonal terms satisfy the condition $m \neq i, n \neq j,(m \pm i)=$ odd, and $(n \pm j)=$ odd. 
For $(m \pm n)=$ odd (antisymmetric buckling):

\begin{tabular}{|c|c|c|c|c|c|c|c|c|c|c|c|c|}
\hline$m, n \backslash^{i, j}$ & $A_{12}$ & $A_{21}$ & $A_{14}$ & $A_{23}$ & $A_{32}$ & $A_{41}$ & $A_{16}$ & $A_{25}$ & $A_{34}$ & $A_{43}$ & $A_{52}$ & $A_{61}$ \\
\hline$m=1, n=2$ & $\frac{M_{12}}{k_{x y}}$ & $-\frac{4}{9}$ & 0 & $\frac{4}{5}$ & 0 & $-\frac{8}{45}$ & 0 & $\frac{20}{63}$ & 0 & $\frac{8}{25}$ & 0 & $-\frac{4}{35}$ \\
\hline$m=2, n=1$ & & $\frac{M_{21}}{k_{z y}}$ & $-\frac{8}{45}$ & 0 & $\frac{4}{5}$ & 0 & $-\frac{4}{35}$ & 0 & $\frac{8}{25}$ & 0 & $\frac{20}{63}$ & 0 \\
\hline$m=1, n=4$ & & & $\frac{M_{\lambda 4}}{k_{x y}}$ & $-\frac{8}{7}$ & 0 & $-\frac{16}{225}$ & 0 & $\frac{40}{27}$ & 0 & $-\frac{16}{35}$ & 0 & $-\frac{8}{175}$ \\
\hline$m=2, n=3$ & & & & $\frac{M_{23}}{k_{x y}}$ & $-\frac{36}{25}$ & 0 & $-\frac{4}{9}$ & 0 & $\frac{72}{35}$ & 0 & $-\frac{4}{7}$ & 0 \\
\hline$m=3, n=2$ & & & & & $\frac{M_{32}}{k_{x y}}$ & $-\frac{8}{7}$ & 0 & $-\frac{4}{7}$ & 0 & $\frac{72}{35}$ & 0 & $-\frac{4}{9}$ \\
\hline$m=4, n=1$ & & & & & & $\frac{M_{u 1}}{k_{x y}}$ & $-\frac{8}{175}$ & 0 & $-\frac{16}{35}$ & 0 & $\frac{40}{27}$ & 0 \\
\hline$m=1, n=0$ & & & & metry & & & $\frac{M_{16}}{k_{x y}}$ & $-\frac{20}{11}$ & 0 & $-\frac{8}{45}$ & 0 & $-\frac{36}{1225}$ \\
\hline$m=2, n=8$ & & & & & & & & $\frac{M_{2 B}}{k_{z y}}$ & $-\frac{8}{3}$ & 0 & $-\frac{100}{441}$ & 0 \\
\hline$m=3, n=4$ & & & & & & & & & $\frac{M_{34}}{k_{x y}}$ & $-\frac{144}{49}$ & 0 & $-\frac{8}{45}$ \\
\hline$m=4, n=3$ & & & & & & & & & & $\frac{M_{\Delta 3}}{k_{x y}}$ & $-\frac{8}{3}$ & 0 \\
\hline$m=5, n=2$ & & & & & & & & & & & $\frac{M_{b 2}}{k_{z y}}$ & $-\frac{20}{11}$ \\
\hline$m=6, n=1$ & & & & & & & & & & & & $\frac{M_{51}}{k_{x y}}$ \\
\hline
\end{tabular}

where the nonzero off-diagonal terms satisfy the conditions $m \neq i, n \neq j,(m \pm i)=$ odd, and $(n \pm j)=$ odd.

Notice that the diagonal terms in equations (11) and (12) came from the first term of equation (1), and the series term of equation (1) gives the off-diagonal terms of the matrices. The $12 \times 12$ determinant was found to give sufficiently accurate eigenvalue solutions.

\section{NUMERICAL RESULTS}

Numerical buckling studies were performed on sandwich panels having MMC face sheets of different fiber orientations. The loading in $y$-axis was set to zero (i.e., $k_{y}=0$, eq. (4)). Thus, the combined loading implies the inplane uniaxial compression in $x$-direction and shear. 


\section{Physical Properties of Panels}

The sandwich panels analyzed have the following geometry: $a=a_{o}=60.96 \mathrm{~cm}(24 \mathrm{in}$.$) , or a b=a_{o}^{2}, \frac{b}{a}=$ $0.1 \sim 4, h=3.0480 \mathrm{~cm}(1.2 \mathrm{in}),. h_{c}=h-t_{s}=2.9667 \mathrm{~cm}(1.1680 \mathrm{in}$.$) , and t_{s}=0.08128 \mathrm{~cm}(0.0320 \mathrm{in}$.). The effective material properties used for titanium honeycomb core are shown in table 1. And the two types of laminated MMC face sheets investigated have the laminate properties listed in table 2.

Table 1. Material properties of titanium honeycomb.

\begin{tabular}{ccc}
\hline \hline $\begin{array}{c}\text { Temperature, } \\
{ }^{\circ} \mathrm{C}\left({ }^{\circ} \mathrm{F}\right)\end{array}$ & $\begin{array}{c}G_{c x z}, \\
\mathrm{GPa}\left(10^{5} \mathrm{lb} / \mathrm{in}^{2}\right)\end{array}$ & $\begin{array}{c}G_{c y z}, \\
\mathrm{GPa}\left(10^{5} \mathrm{lb} / \mathrm{in}^{2}\right)\end{array}$ \\
\hline $21.11(70)$ & $1.4365(2.0835)$ & $0.6505(0.9435)$ \\
$315.56(600)$ & $1.2480(1.8100)$ & $0.5652(0.8197)$ \\
$648.89(1200)$ & $0.8277(1.2005)$ & $0.4527(0.6566)$ \\
\hline
\end{tabular}

Table 2. Material properties of laminated MMC face sheets.

\begin{tabular}{cccccc}
\hline $\begin{array}{c}\text { Temperature, } \\
{ }^{\circ} \mathrm{C}\left({ }^{\circ} \mathrm{F}\right)\end{array}$ & $\begin{array}{c}E_{x}, \\
\mathrm{GPa}\left(10^{6} \mathrm{lb} / \mathrm{in}^{2}\right)\end{array}$ & $\begin{array}{c}E_{y}, \\
\mathrm{GPa}\left(10^{6} \mathrm{lb} / \mathrm{in}^{2}\right)\end{array}$ & $\mathrm{GPa}\left(10^{6} \mathrm{lb} / \mathrm{in}^{2}\right)$ & $\nu_{x y}=\nu_{y x}$ \\
\hline \multicolumn{5}{c}{$[90 / 0 / 0 / 90]$ laminate } \\
\hline 21.11 & $(70)$ & $158.3581(22.9679)$ & $158.3581(22.9679)$ & $56.1923(8.150)$ & 0.2369 \\
315.56 & $(600)$ & $135.0573(19.5884)$ & $135.0573(19.5884)$ & $40.6791(5.900)$ & 0.2108 \\
$648.89(1200)$ & $110.8008(16.0703)$ & $110.8008(16.0703)$ & $24.1317(3.500)$ & 0.1634 \\
\hline \multicolumn{6}{c}{$[45 /-45 /-45 / 45]$ laminate } \\
\hline 21.11 & $(70)$ & $145.8551(21.1545)$ & $145.8551(21.1545)$ & $64.0130(9.2843)$ & 0.2972 \\
315.56 & $(600)$ & $110.2837(15.9953)$ & $110.2837(15.9953)$ & $55.7731(8.0892)$ & 0.3555 \\
$648.89(1200)$ & $70.7457(10.2608)$ & $70.7457(10.2608)$ & $47.6193(6.9066)$ & 0.4658 \\
\hline
\end{tabular}

Finally, for the value of $D^{*}$ (eq. (4)), the room temperature material properties of $\mathrm{Ti}-6-4$ were used, namely, $E_{\mathrm{Ti}}=110.3161 \mathrm{GPa}\left(16 \times 10^{6} \mathrm{lb} / \mathrm{in}^{2}\right), \nu_{\mathrm{Ti}}=0.31$. 


\section{Buckling Curves}

\section{Conventional Plots}

In the conventional plots of buckling interaction curves, the panel length $a$ is kept constant (i.e., $a=a_{o}=$ constant). Figure 2 shows a family of buckling interaction curves calculated from equation (1) for the sandwich panels with two different types of laminated face sheets. The buckling interaction curves are plotted for different panel aspect ratios $\frac{b}{a}$ and different temperatures using data given in tables 1 and 2 . For $\frac{b}{a}=0.7$, each buckling interaction curve is a combination of symmetric and antisymmetric buckling interaction curves. For compressiondominated loadings the panels will buckle antisymmetrically. For shear-dominated loadings the buckling mode is symmetrical. For $\frac{b}{a}=1$ (square panel), all buckling interaction curves are continuous and are associated with

symmetric buckling. The antisymmetric buckling interaction curves for $\frac{b}{a}=1$ (not shown) which give much higher buckling loads, do not intersect with the symmetrical buckling curves. For $\frac{b}{a}=2,3,4$, the buckling interaction curves are discontinuous, and are the composite curves consisting of both symmetric and antisymmetric buckling interaction curve segments. For $\frac{b}{a} \leq 1$, the $[45 /-45 /-45 / 45]$ lamination case has higher combined buckling strength as compared with the [90/0/0/90] lamination case. As the temperature increases, the buckling strength of the latter decreases slightly faster than the former. For $\frac{b}{a}=2$, the two lamination cases have comparable compressiondominated buckling strength. But for shear-dominated buckling, the $[45 /-45 /-45 / 45]$ lamination case is slightly superior to the $[90 / 0 / 0 / 90]$ lamination case. For $\frac{b}{a}=3,4$, the $[90 / 0 / 0 / 90]$ lamination case has slightly higher compression-dominated buckling strength than the $[45 /-45 /-45 / 45]$ lamination. For shear-dominated bucklings, the reverse is true.

Even though the $[45 /-45 /-45 / 45]$ lamination case has lower values of bending stiffness $\left\{D_{x}, D_{y}\right\}$ (or $\left\{E_{x}, E_{y}\right\}$, table 2) than the [90/0/0/90] lamination case, it has higher values of $D_{x y}$ (or $G_{x y}$, table 2) than the latter for all temperature levels. Because the combined-load buckling strength of panels depend not only on $\left\{D_{x}, D_{y}\right\}$ but also on $D_{x y}$ (eqs. (1), (4), and (5) through (10)), the combination of the values of $D_{x}, D_{y}$, and $D_{x y}$ happened to cause the $[45 /-45 /-45 / 45]$ lamination case to have slightly superior buckling strength than the $[90 / 0 / 0 / 90]$ lamination case. 
Figure 3 compares the room temperature $\left(T=21.11^{\circ} \mathrm{C}\left(70^{\circ} \mathrm{F}\right)\right)$ buckling interaction curves of the $\frac{b}{a}=0.7$ sandwich panels fabricated with MMC face sheets (taken from fig. 2) and with monolithic titanium face sheets, under the condition of equal panel specific weight. ${ }^{3}$ Notice that through the fiber reinforcement of the face sheets, the buckling strength of the sandwich panel could be increased by 27 percent in pure uniaxial compression and by 22 percent in pure shear.

Figures 4 and 5, respectively, show the decreases of the compressive and shear bucking strengths $\left(k_{x}, k_{x y}\right)$ of the two types of MMC sandwich panels with the increase of the panel aspect ratio $\frac{b}{a}$. The compressive buckling strength $k_{x}$ (fig. 4) decreases very sharply with the increase of $\frac{b}{a}$ in the region $\frac{b}{a}<1$, and beyond $\frac{b}{a}=2$, the rate of decrease of $k_{x}$ gradually dies out. For low panel aspect ratio $\left(\frac{b}{a}<0.75\right)$, the buckling mode is antisymmetrical, and beyond $\frac{b}{a}=0.75$, the panel will buckle symmetrically. The shear buckling strength $k_{x y}$ (fig. 5 ) is less sensitive to the change of $\frac{b}{a}$. All shear buckling curves shown in figure 5 are composite curves constructed with symmetrical and antisymmetrical buckling curves.

Figure 6 shows the degradation of $k_{x}$ of pure compression, and $k_{x y}$ of pure shear with the increase in temperature for the panel with aspect ratio $\frac{b}{a}=0.7$. The $[45 /-45 /-45 / 45]$ lamination case has a lower rate of degradation of $k_{x}$ and $k_{x y}$ with temperature than the $[90 / 0 / 0 / 90]$ lamination case.

\section{Modified Plots}

In the modified plots of the buckling curves, the panel area is kept constant ( $a b=a_{0}^{2}=$ constant). The conventional plots shown in figures 4 and 5 may not serve as ideal design curves for aerospace structural panels because, when the panel aspect ratio $\frac{b}{a}$ is changed (holding $a$ constant), the panel weight (or panel area $a b$ ) is also changed accordingly. In aerospace structural designs, the main objective is structural optimization. That is, for a given panel weight, the objective is to search for a panel with optimum buckling strengths (or stiffness). For this reason, $k_{x}$ and $k_{x y}$ were recalculated as functions of $\frac{b}{a}$ under the condition $a b=a_{o}^{2}=$ constant (instead of $a=a_{o}=$ constant). Figures 7 and 8 respectively show the modified buckling plots of $\bar{k}_{x}$ as a function of $\frac{b}{a}$ and $\bar{k}_{x y}$ as a function of $\frac{b}{a}$ when the panel area $a b$ was held constant. In practical applications, the structural panels have to be supported by edge frames, and, therefore, the weight of the edge frames must be considered in the structural optimizations. If the cross sections 
of the edge frames, are kept constant, the edge frame weight becomes a function of edge length $2(a+b)$. Thus, in figures 7 and 8 the dimensionless semi-edge length $\frac{a+b}{2 a_{o}}$ was also plotted as a function of $\frac{b}{a}$. Figures 7 and 8 serve as design curves for selecting the optimum sandwich panel geometry (i.e., the panel aspect ratio $\frac{b}{a}$ ). A square panel $\left(\frac{b}{a}=1\right)$ has the minimum edge frame weight; however, it has comparatively low compressive buckling strength (fig. 7), and it has practically lowest shear buckling strength (fig. 8). The aspect ratios $\frac{b}{a}$ at which either $\bar{k}_{x}$ (fig. 7) or $\bar{k}_{x y}$ (fig. 8) becomes minimum are listed in table 3 .

Table 3. Panel aspect ratios at which $\bar{k}_{x}$ or $\bar{k}_{x y}$ is minimum.

\begin{tabular}{cccccc}
\hline \hline \multirow{2}{*}{$\begin{array}{c}\text { Temperature, } \\
{ }^{\circ} \mathrm{C}\left({ }^{\circ} \mathrm{F}\right)\end{array}$} & \multicolumn{2}{c}{$\frac{b}{a}$ for minimum $\bar{k}_{x}$} & & \multicolumn{2}{c}{$\frac{b}{a}$ for minimum $\bar{k}_{x y}$} \\
\cline { 2 - 3 } \cline { 5 - 6 }$(70)$ & $1.85 /-45 /-45 / 45]$ & {$[90 / 0 / 0 / 90]$} & & {$[45 /-45 /-45 / 45]$} & {$[90 / 0 / 0 / 90]$} \\
$315.56(600)$ & 1.9 & 1.7 & & 0.9 & 0.9 \\
$648.89(1200)$ & 2.0 & 1.7 & & 0.9 & 0.9 \\
\hline \hline
\end{tabular}

For pure compression (fig. 7 ), the $[45 /-45 /-45 / 45]$ laminates have slightly higher compressive buckling strengths than the [90/0/0/90] laminates in the region $\frac{b}{a}<2.2$, and the reverse is true when $\frac{b}{a}>2.2$. For pure shear (fig. 8), the $[45 /-45 /-45 / 45]$ laminates are always superior to the $[90 / 0 / 0 / 90]$ laminates for the whole range of panel aspect ratio $\frac{b}{a}$. From figure 7 and 8 , it is noticed that the slender $\left(\frac{b}{a}<1\right)$ rectangular panels are more efficient than the fat $\left(\frac{b}{a}>1\right)$ rectangular panels. When the panel aspect ratio $\frac{b}{a}$ is reduced from $\frac{b}{a}=1$, one can improve the panel compressive buckling strength (fig. 7) considerably with slight edge frame weight penalty. The similar gain in shear buckling strength (fig. 8) is less conspicuous. At higher aspect ratios, the gains in values $\bar{k}_{x}$ (fig. 7) and $\bar{k}_{x y}$ (fig. 8) are practically offset by the edge weight penalty (more severe in $\bar{k}_{x}$ curves (fig. 7)).

\section{Buckling Interaction Surfaces}

Figure 9 shows three dimensional buckling surfaces plotted in $\left\{k_{x}, k_{x y}, \frac{b}{a}\right\}$ and $\left\{\bar{k}_{x}, \bar{k}_{x y}, \frac{b}{a}\right\}$ spaces for conditions $a=a_{o}=$ constant (constant panel length), and $a b=a_{o}^{2}=$ constant (constant panel area), respectively. This figure gives better visualization of the buckling behavior of the sandwich panels than the buckling plots shown in figures 2, $4,5,7$, and 8. For slender rectangular panels $\left(\frac{b}{a}<1\right)$, antisymmetric bucklings occurs mostly in the compressiondominated regions. For wider panels $\left(\frac{b}{a}>1\right)$, the antisymmetric bucklings take place in the shear-dominated regions. In the neighborhood of $\frac{b}{a}=1$, the lowest buckling modes are all symmetric $(m=n=1)$. 


\section{Effect of Fiber Orientations}

Figure 10 shows the room temperature $\left(T=21.11^{\circ} \mathrm{C}\left(70^{\circ} \mathrm{F}\right)\right)$ pure compression buckling strength $\left(k_{x}\right)$ of sandwich panel with $[\theta /-\theta /-\theta / \theta]$ laminated face sheets plotted as a function of fiber angle $\theta$ with panel aspect ratio $\frac{b}{a}$ as a parameter. The peak value of $k_{x}$ occurs at $\theta=20^{\circ}$ for $\frac{b}{a}=0.7$ panel, and migrates to $\theta=60^{\circ}$ for $\frac{b}{a}=0.8$ panel. In the neighborhood of $\frac{b}{a}=1$, the peak $k_{x}$ point occurs near $\theta=45^{\circ}$. As the value of $\frac{b}{a}$ increases, the peak $k_{x}$ point shifts toward $\theta=0^{\circ}$.

This special feature of composite material was also seen in single laminated plates with symmetric angle-ply laminate ${ }^{7}$ and antisymmetric angle-ply laminate. ${ }^{8}$ Similar plots for pure-shear buckling strength $\left(k_{x y}\right)$ are shown in figure 11. The maximum $k_{x y}$ point occurs at $\theta=45^{\circ}$ for $\frac{b}{a} \leq 1$ and gradually moves toward $\theta=0^{\circ}$ as the value of $\frac{b}{a}$ increases beyond $\frac{b}{a}=1$.

\section{CONCLUSIONS}

Combined compressive and shear buckling analysis was performed on flat rectangular sandwich panels fabricated with titanium honeycomb core and laminated metal matrix composite face sheets of $[45 /-45 /-45 / 45]$ and $[90 / 0 / 0 / 90]$ laminations. The results of the analysis may be summarized in the following.

1. The $[45 /-45 /-45 / 45]$ lamination case has slightly superior compressive buckling strength than the $[90 / 0 / 0 / 90]$ lamination case for panel aspect ratios $\frac{b}{a}<2.2$, beyond which the reverse is true.

2. The $[45 /-45 /-45 / 45]$ lamination case has superior shear buckling strength than the $[90 / 0 / 0 / 90]$ lamination case for the whole range of panel aspect ratios.

3. Through fiber reinforcement, the compressive and shear buckling strength may be increased from the monolithic face sheet case by about 27 and 22 percent, respectively.

4. Degradation of buckling strength of the sandwich panel with rising temperature is faster in shear than in compression.

5. The geometry of desired high efficiency sandwich panels is slightly slender (i.e., $\frac{b}{a}<1$ ) rectangular panels. 
6. The optimum fiber orientation of the face sheets for the highest combined-load buckling strength of the sandwich panel is a strong function of both loading condition $\left(k_{x}\right.$ or $\left.k_{y}\right)$ and panel aspect ratio $\frac{b}{a}$.

\section{REFERENCES}

1. Taya, Minoru and Richard J. Arsenault, Metal Matrix Composites: Thermomechanical Behavior, Pergamon Press, NY, 1989.

2. Tenny, Darrel R., W. Barry Lisagor, and Sidney C. Dixon, "Materials and Structures for Hypersonic Vehicles," J. Aircraft, vol. 26, no. 11, Nov. 1989, pp. 953-970.

3. Ko, William L. and Raymond H. Jackson, Combined Compressive and Shear Buckling Analysis of Hypersonic Aircraft Structural Sandwich Panels, NASA TM-4290, 1991. Also AIAA paper no. 92-2487-CP, presented at the 33rd AIAA/ASME/ASCE/AHS/ASC Structures, Structural Dynamics and Materials Conference, Dallas, Texas, April 13-15, 1992.

4. Bert, Charles W. and K.N. Cho, "Uniaxial Compressive and Shear Buckling in Orthotropic Sandwich Plates By Improved Theory," AIAA 86-0977, May 1986.

5. Batdorf, S.B. and Manuel Stein, Critical Combinations of Shear and Dinect Stress for Simply Supported Rectangular Flat Plates, NACA TN-1223, 1947.

6. Stein, Manuel and John Neff, Buckling Stresses of Simply Supported Rectangular Flat Plates in Shear, NACA TN-1222, 1947.

7. Aston, J.E. and J.M. Whitney, Theory of Laminated Plates, Technomic Publishing Co., Westport, Connecticut, 1970.

8. Jones, Robert M., Harold S. Morgan, and James M. Whitney, "Buckling and Vibration of Antisymmetrically Laminated Angle-Ply Rectangular Plates," J. Appl. Mech., vol. 40, no. 4, Dec. 1973, pp. 1143-1144. 


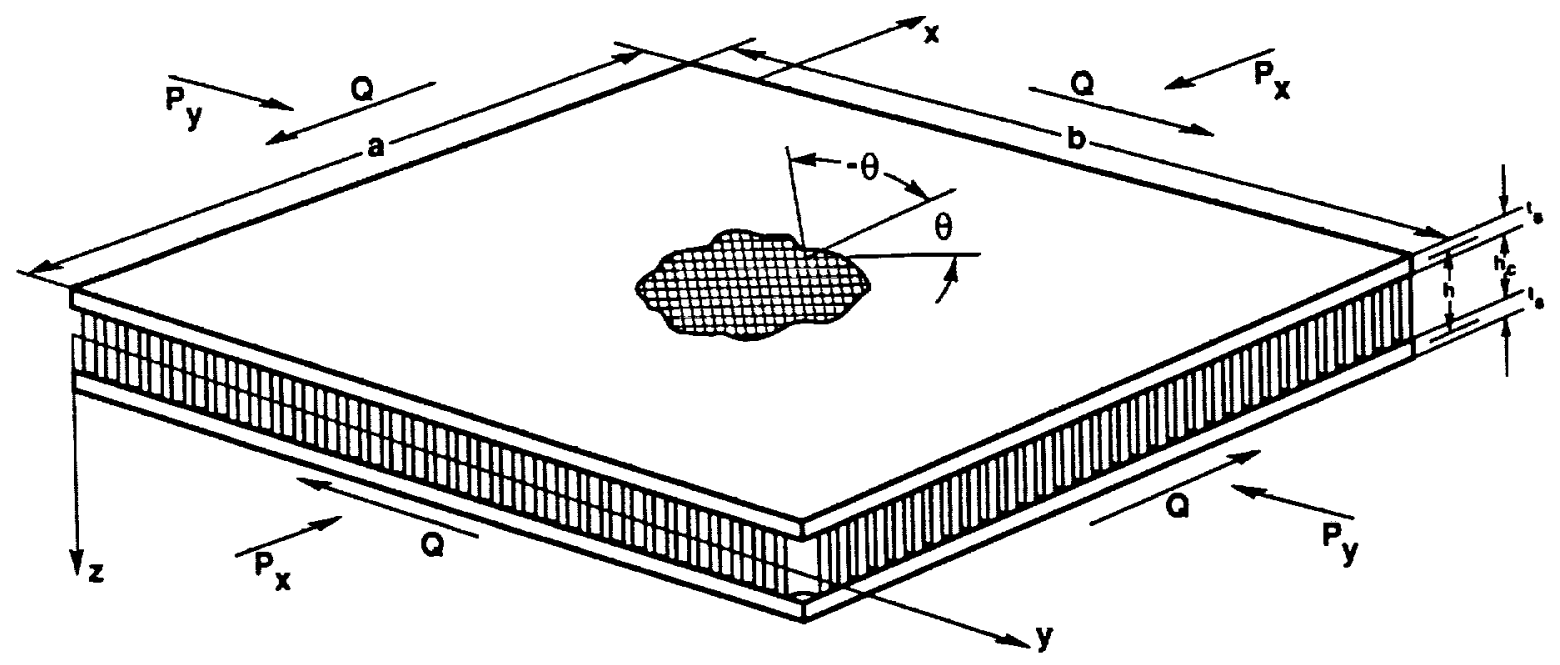

910383

Figure 1. Honeycomb-core sandwich panel with MMC face sheets subjected to combined compressive and shear loadings.

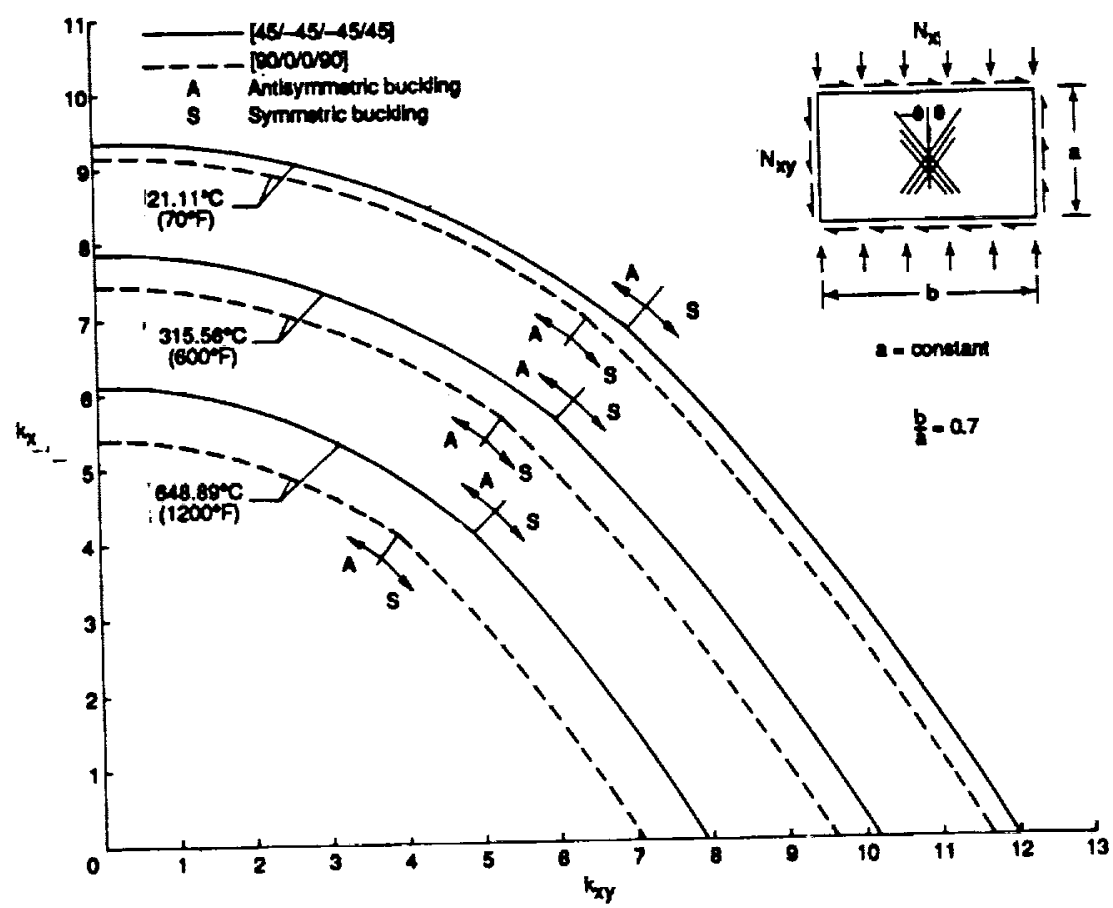

Figure 2. Buckling interaction curves for MMC sandwich panels at different temperatures; constant panel length. 

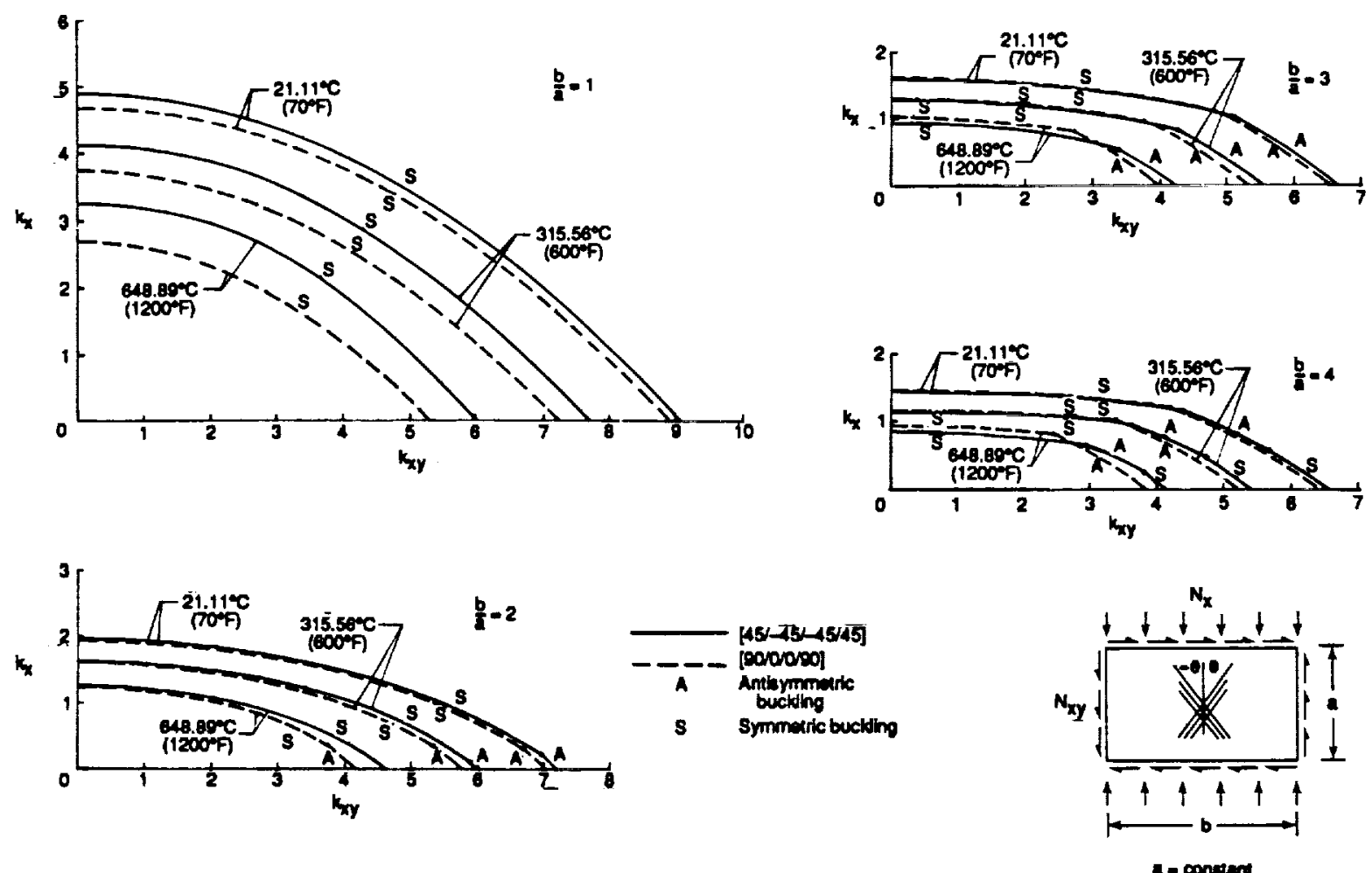

Figure 2. Concluded.

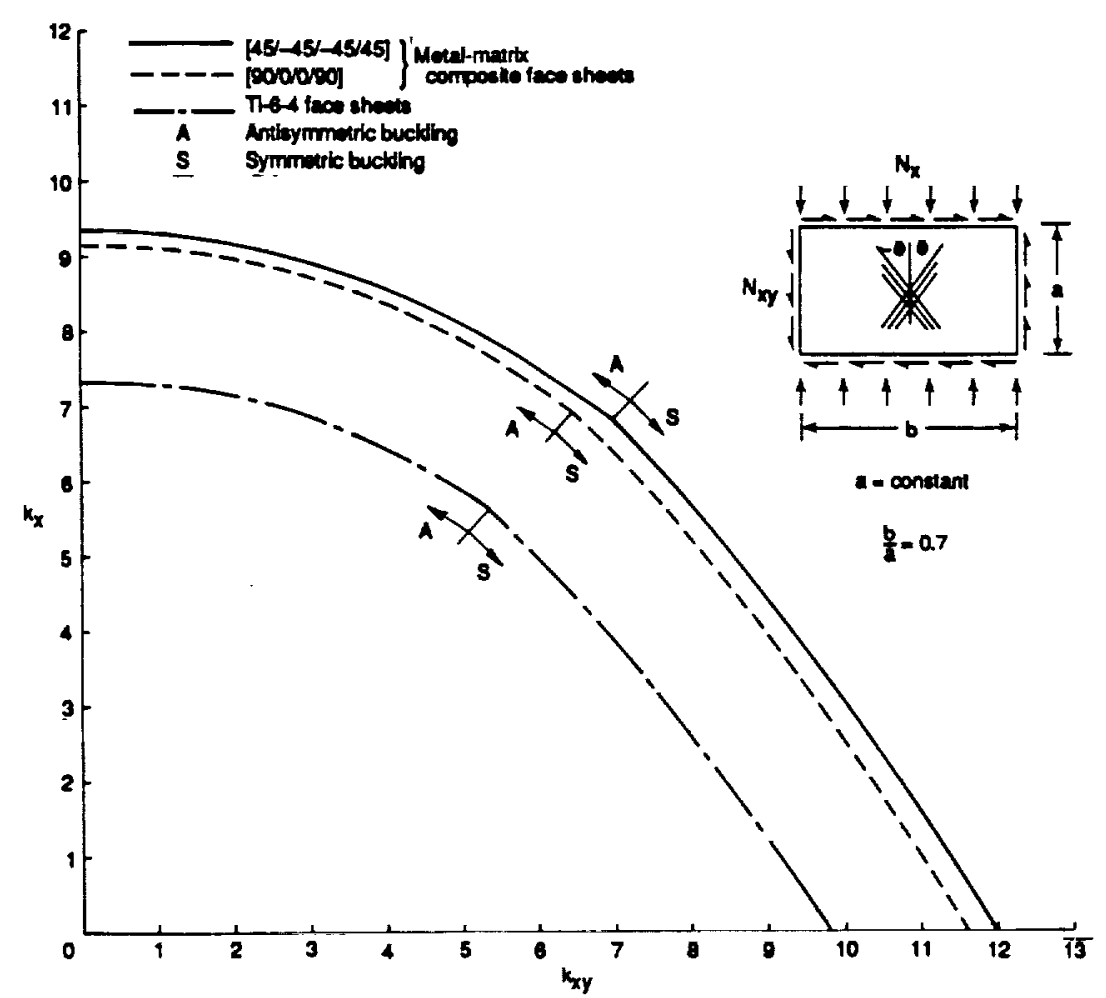

Figure 3. Comparison of buckling strengths of honeycomb-core sandwich panels of same specific weight fabricated with different face sheet materials; $T=21.11^{\circ} \mathrm{C}\left(70^{\circ} \mathrm{F}\right)$; constant panel length. 


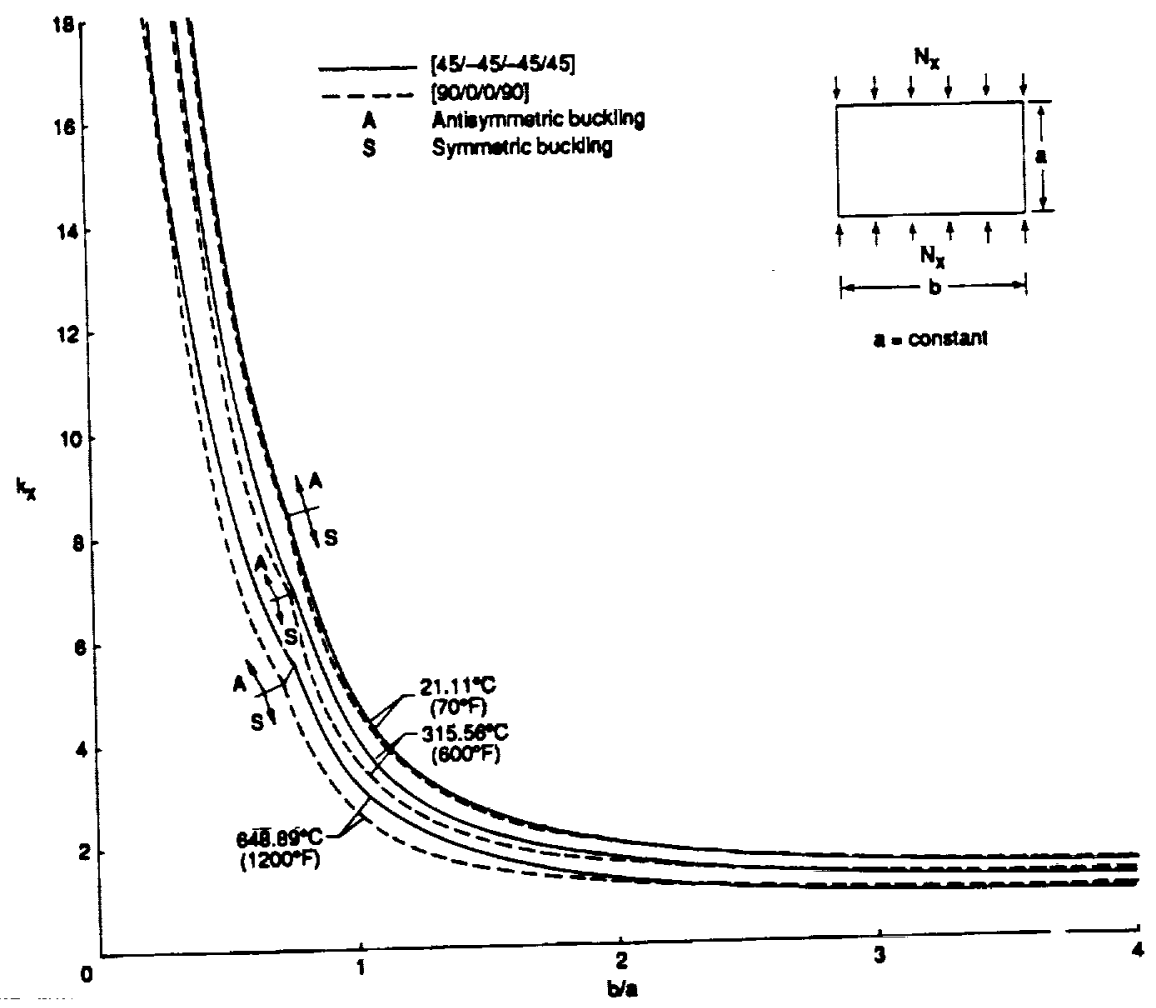

Figure 4. Degradation of compressive buckling strengths of MMC sandwich panels with increasing temperatures and panel aspect ratio; constant panel length.

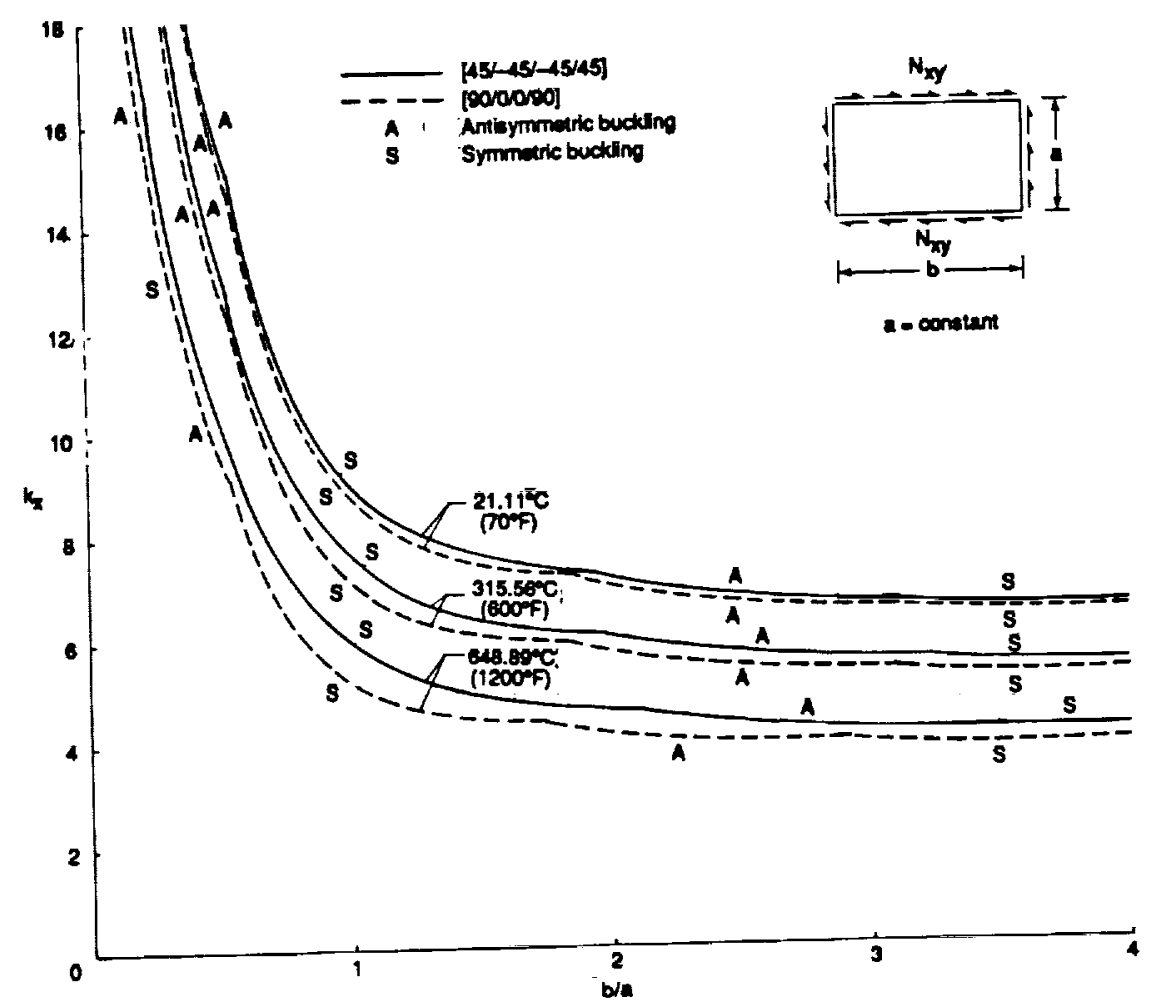

Figure 5. Degradation of shear buckling strengths of MMC sandwich panels with increasing temperatures and panel aspect ratio; constant panel length. 


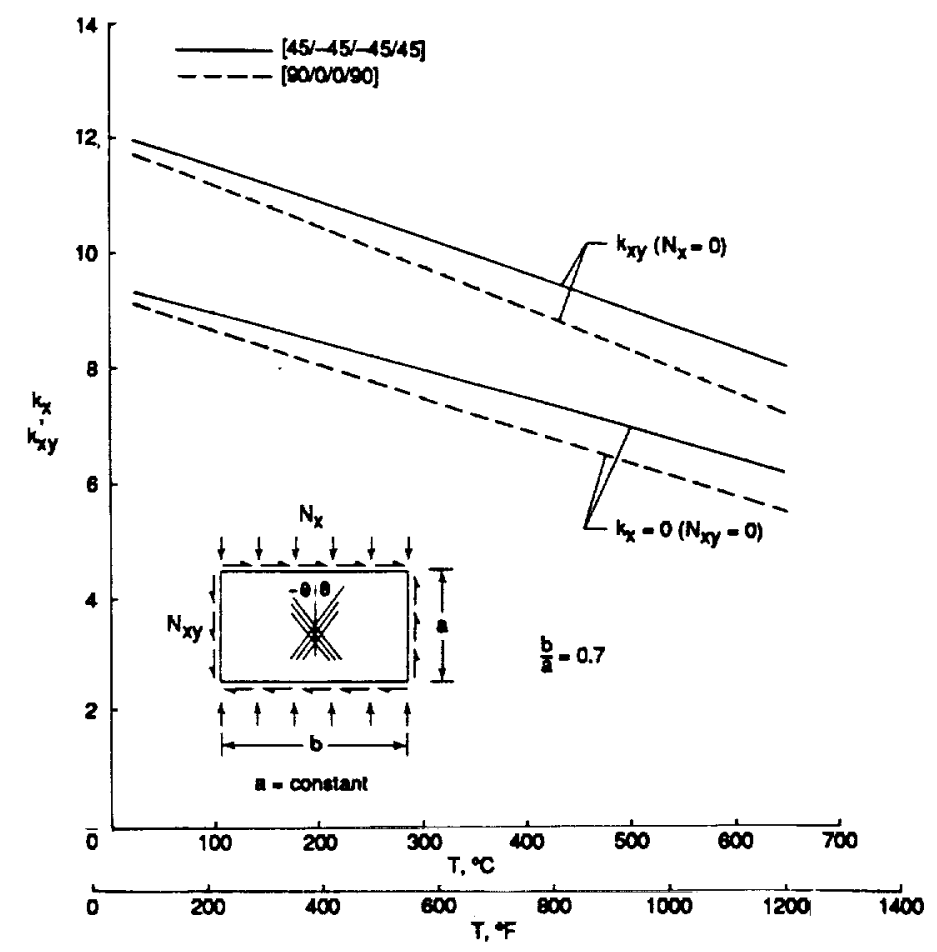

Figure 6. Degradation of pure compressive and pure shear buckling strengths of MMC sandwich panels with increasing temperatures; $b / a=0.7$; constant panel length.

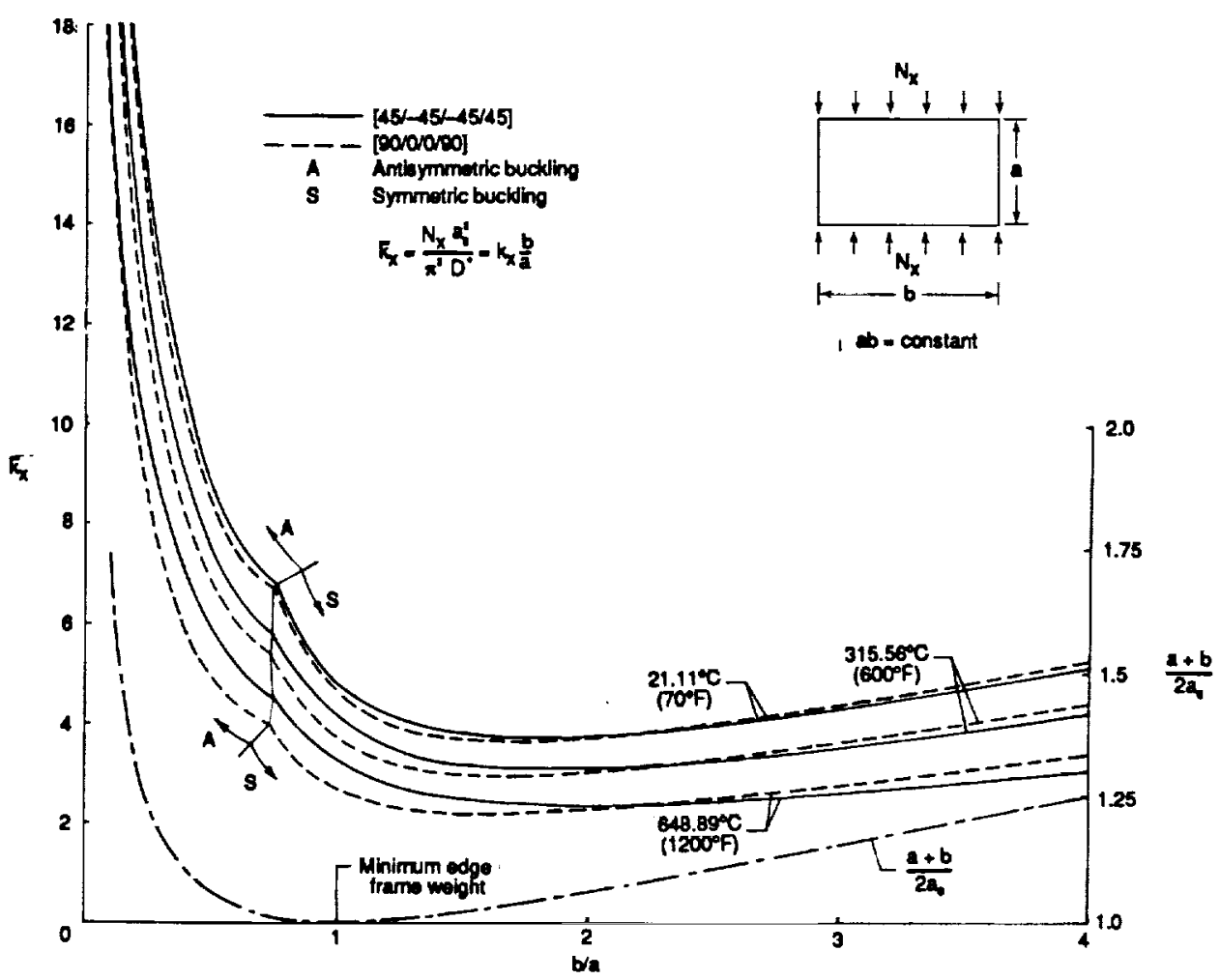

Figure 7. Degradation of compressive buckling strengths of MMC sandwich panels with increasing temperatures and change of panel aspect ratio; constant panel areas. 


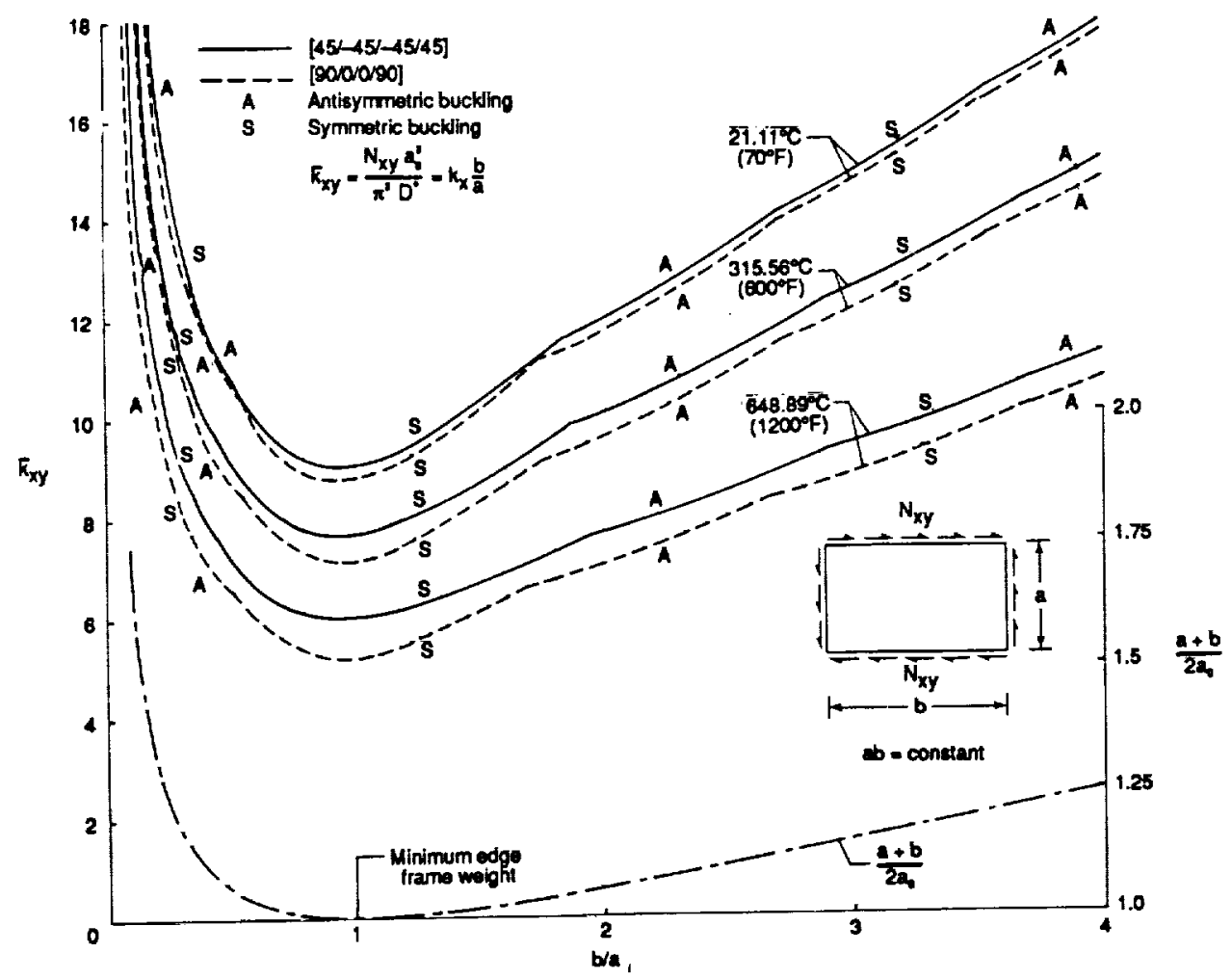

Figure 8. Degradation of shear buckling strengths of MMC sandwich panels with increasing temperatures and change of panel aspect ratio; constant panel areas.

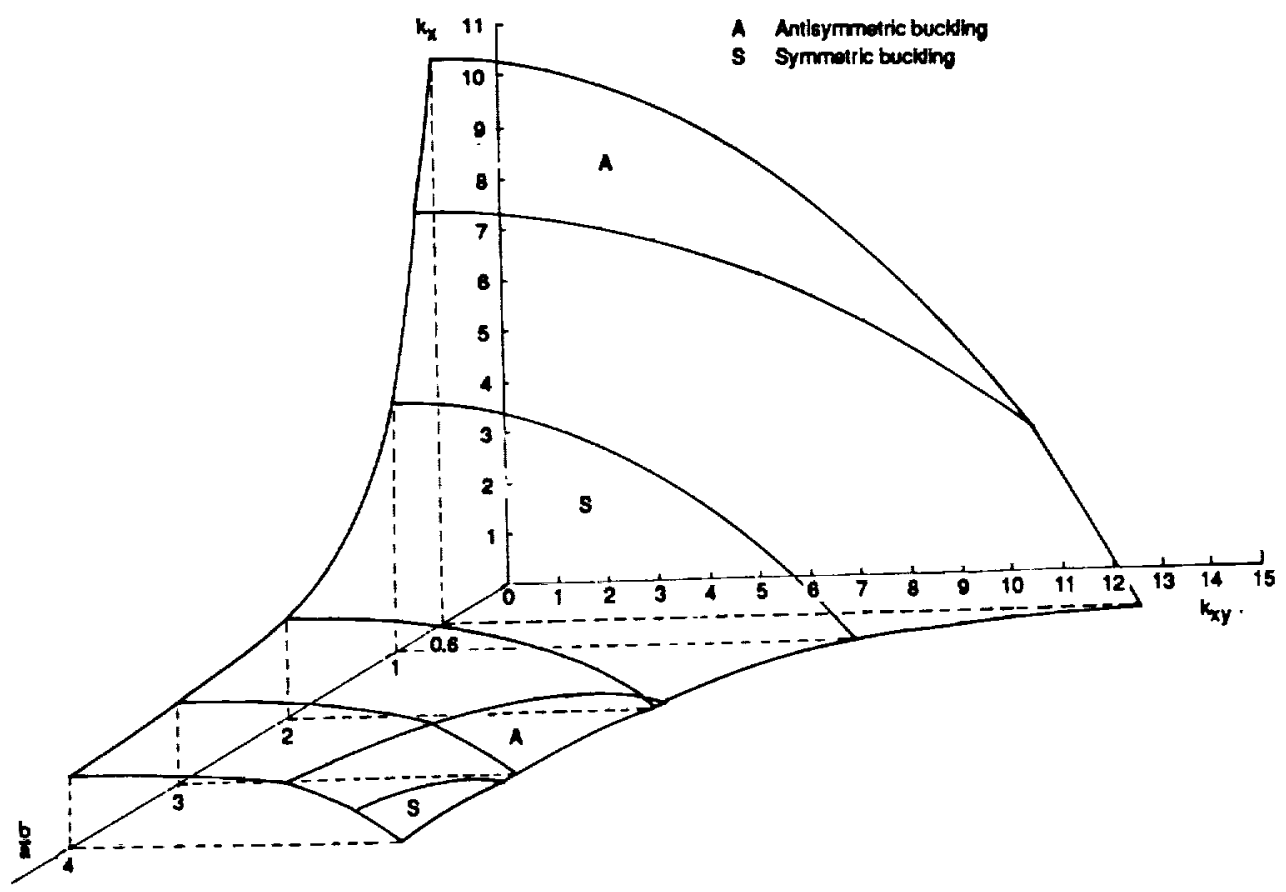

(a) $a=$ constant.

Figure 9. Buckling interaction surfaces for MMC sandwich panels; $[45 /-45 /-45 / 45]$ face sheets; $T=21.11^{\circ} \mathrm{C}\left(70^{\circ} \mathrm{F}\right)$. 


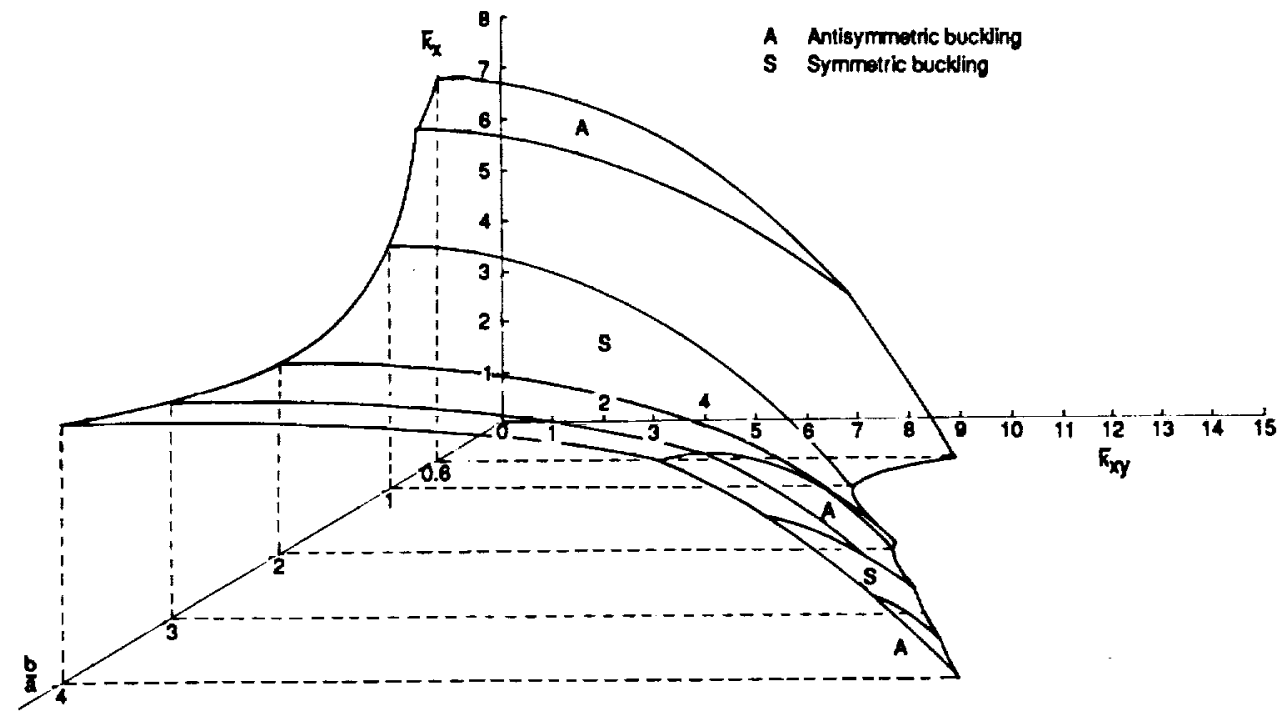

(b) $a b=$ constant.

Figure 9. Concluded.

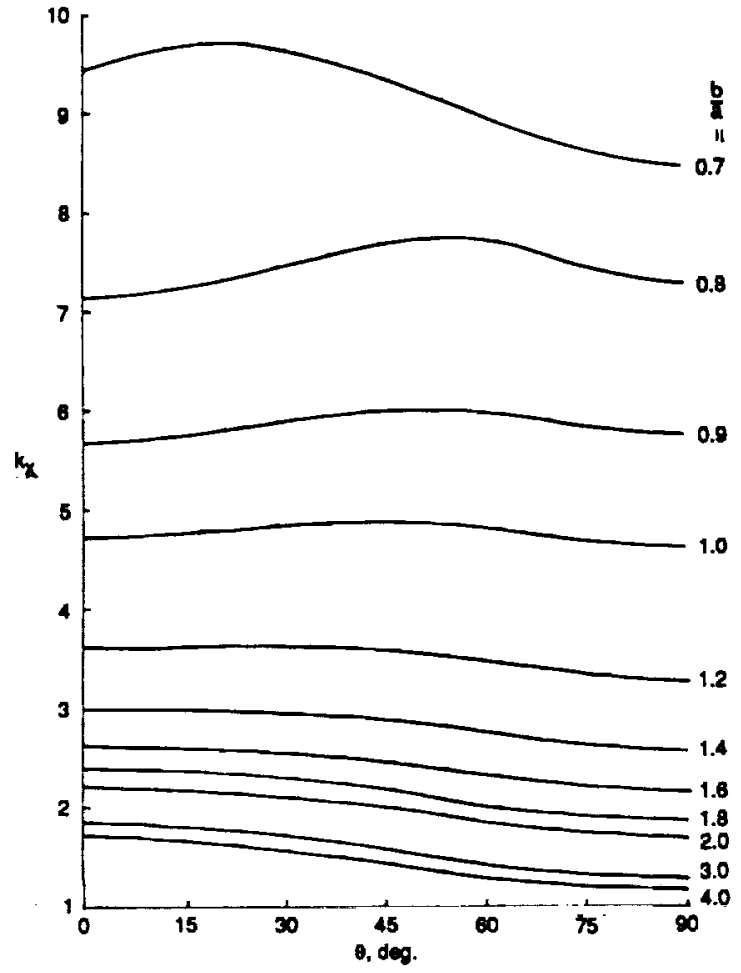

' Figure 10. Effect of fiber orientation on compressive buckling strengths of MMC sandwich panels; $T=$ $21.11^{\circ} \mathrm{C}\left(70^{\circ} \mathrm{F}\right)$.

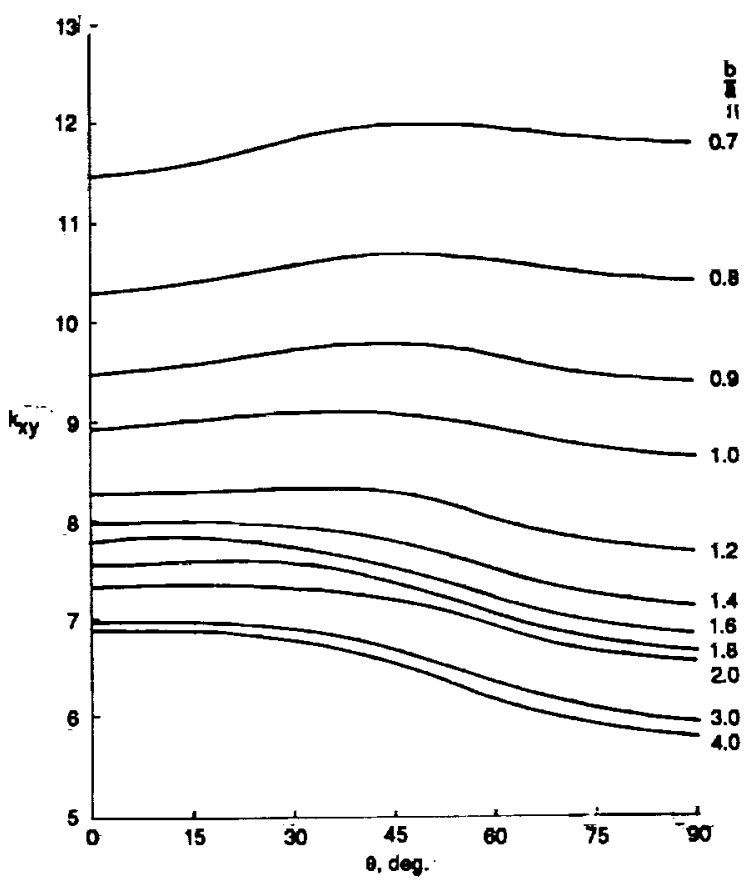

Figure 11. Effect of fiber orientation on shear buckling strengths of MMC sandwich panels; $T=21.11^{\circ} \mathrm{C}$ $\left(70^{\circ} \mathrm{F}\right)$. 
Public reporting burden for this collection of information is estimated to average t hour per response. Including the time for reviewing instructions, seachling existing data sources, gathering and maimaining the data noeded, and comploting and reviowing the collocilon of intormallon. Sond comiments

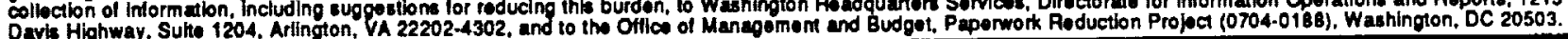

\begin{tabular}{|l|l|l}
\hline 1. AGENCY USE ONLY (Leave blank) & $\begin{array}{l}\text { 2. REPORT DATE } \\
\text { June } 1993\end{array}$ & $\begin{array}{l}\text { 3. REPORT TYPE AND DATES COVERED } \\
\text { Technical Memorandum }\end{array}$ \\
\hline
\end{tabular}

\section{TITLE AND SUBTITLE}

Compressive and Shear Buckling Analysis of Metal Matrix Composite Sandwich Panels Under Different Thermal Environments

\section{AUTHOA(S)}

William L. Ko and Raymond H. Jackson

7. PERFoRMING ORgANIZATION NAME(S) AND ADDAESS(ES)

B. PERFORMING ORGANIZATION REPORT NUMBER

NASA Dryden Flight Research Facility

P.O. Box 273

H-1900

Edwards, California 93523-0273

9. SPONSORING/MONITORING AGENCY NAME(S) AND ADDRESS(ES)

National Aeronautics and Space Administration

Washington, DC 20546-0001

WU-505-63-40

10. SPONSORINGIMONITORING AGENCY REPORT NUMBER

NASA TM-4492

\section{SUPPLEMENTARY NOTES}

Prepared for the 7th International Conference on Composite Structures, University of Paisley, Paisley, Scotland, July 1993.

\begin{tabular}{l|l}
\hline 12a. DISTAIBUTION/AVAILABILITY STATEMENT & 12b. DISTRIBUTION CODE \\
Unclassified - Unlimited & \\
Subject Category 39 &
\end{tabular}

13. ABSTRACT (Maximum 200 words)

Combined inplane compressive and shear buckling analysis was conducted on flat rectangular sand wich panels using the Raleigh-Ritz minimum energy method with a consideration of transverse shear effect of the sandwich core. The sand wich panels were fabricated with titanium honeycomb core and laminated metal matrix composite face sheets. The results show that slightly slender (along unidirectional compressive loading axis) rectangular sandwich panels have the most desirable stiffness-to-weight ratios for aerospace structural applications; the degradation of buckling strength of sandwich panels with rising temperature is faster in shear than in compression; and the fiber orientation of the face sheets for optimum combined-load buckling strength of sandwich panels is a strong function of both loading condition and panel aspect ratio. Under the same specific weight and panel aspect ratio, a sandwich panel with metal matrix composite face sheets has much higher buckling strength than one having monolithic face sheets.

\section{SUBJECT TERMS}

Combined load buckling; Buckling interaction surfaces; Metal matrix composites; Sandwich panels

\begin{tabular}{|c|c|c|c|}
\hline $\begin{array}{l}\text { 17. SECURITY CLASSIFICATION } \\
\text { OF REPORT } \\
\text { Unclassified }\end{array}$ & $\begin{array}{l}\text { 18. SECURITY CLASSIFICATION } \\
\text { OF THIS PAGE } \\
\text { Unclassified }\end{array}$ & $\begin{array}{l}\text { 19. SECURITY CLASSIFICATION } \\
\text { OF ABSTRACT } \\
\text { Unclassified }\end{array}$ & $\begin{array}{l}\text { 20. LIMITATION OF ABSTRACT } \\
\text { Unlimited }\end{array}$ \\
\hline $1-280-5500$ & MD 21090; (301)62 & & $\begin{array}{l}\text { scribed by ANSI Std. } 230-10 \\
-102\end{array}$ \\
\hline
\end{tabular}

